\title{
Pelvic floor function and advanced maternal age at first vaginal delivery
}

\author{
Mikako Yoshida ${ }^{1}$, Ryoko Murayama ${ }^{2}$, Maki Nakata ${ }^{3}$, Megumi Haruna ${ }^{4}$, Masayo Matsuzaki ${ }^{4}$, \\ Mie Shiraishi ${ }^{4}$, Hiromi Sanada ${ }^{1}$ \\ ${ }^{1}$ Department of Gerontological Nursing/Wound Care Management, Graduate School of Medicine, The University of Tokyo, Tokyo, \\ Japan \\ ${ }^{2}$ Department of Advanced Nursing Technology, Graduate School of Medicine, The University of Tokyo, Tokyo, Japan \\ ${ }^{3}$ Department of Obstetrics and Gynecology, Mitsui Memorial Hospital, Tokyo, Japan \\ ${ }^{4}$ Department of Midwifery and Women's Health, Graduate School of Medicine, The University of Tokyo, Tokyo, Japan \\ Email: hsanada-tky@umin.ac.jp
}

Received 27 March 2013; revised 28 April 2013; accepted 6 May 2013

Copyright (C) 2013 Mikako Yoshida et al. This is an open access article distributed under the Creative Commons Attribution License, which permits unrestricted use, distribution, and reproduction in any medium, provided the original work is properly cited.

\begin{abstract}
Purpose: The study aimed to show differences in temporal recovery of pelvic floor function within 6 months postpartum between women having their first delivery at an advanced age and those having their first delivery at a younger age. Methods: Seventeen women (age: $35.5 \pm 3.5$, BMI: $21.1 \pm 3.2$ ) were studied at about 6 weeks, 3 months, and 6 months after vaginal delivery. Urinary incontinence was assessed by the International Consultation on Incontinence Questionnaire-Short Form. Pelvic floor function was assessed by the anteroposterior diameter of the levator hiatus using transperineal ultrasound. Women who delivered for the first time at 35 years and/or older were defined as being of advanced maternal age. Results: Nine of 17 women (52.9\%) were of advanced maternal age and 5 experienced postpartum stress urinary incontinence. Four of these 5 women $(\mathbf{8 0 . 0} \%)$ were of advanced maternal age. The anteroposterior diameter of the levator hiatus at rest was significantly greater in the advanced maternal age women than in the younger maternal age women at 3 and 6 months postpartum $(p<0.01)$. Among the continent women, the anteroposterior diameter of the levator hiatus at rest was significantly greater in the advanced maternal age women than in the younger maternal age women at 6 months postpartum $(p=0.004)$. However, among the advanced maternal age women, all parameters of the anteroposterior diameter of the levator hiatus were not significantly different between the women with and without stress urinary continence. Conclusion: Recovery of pelvic floor function following delivery may be delayed in women of advanced mater-
\end{abstract}

nal age at first delivery because of the damage to the pelvic floor during pregnancy and vaginal delivery, resulting in increase in the incidence of stress urinary incontinence.

Keywords: Advanced Maternal Age; Pelvic Floor; Stress Urinary Incontinence; Ultrasound; Vaginal Delivery

\section{INTRODUCTION}

Urinary incontinence is a common problem resulting in impaired quality of life in women [1,2]. The prevalence of urinary incontinence after delivery among parous women is $20 \%-30 \%$, and the most common symptom of urinary incontinence is stress urinary incontinence [3-7]. Major factors of stress urinary incontinence are increasing number of births, vaginal delivery, and heavier babies $[4,7]$ since the pelvic floor is damaged by the weight of the fetus during pregnancy and passage of the fetus during vaginal delivery through the pelvic cavity [8-11]. Some epidemiological studies have clearly demonstrated a causal relationship between advanced maternal age and stress urinary incontinence [4,12-14]. This relationship is a concern in Japan because more and more women bear children at a later age [15]. However, how childbirth at a later age affects the urinary continence mechanism is unclear because of a paucity of research outside of epidemiological studies.

In pathophysiology, postpartum stress urinary incontinence may be considered to result from an imbalance between damage to the pelvic floor during pregnancy and vaginal delivery and recovery of the damaged pelvic floor during the postpartum period. With regard to the 
damage to the pelvic floor during vaginal delivery, DeLancey et al. [16] reported that women with stress urinary incontinence were twice as likely to have detected damage of the pelvic floor in the postpartum period. In the same cohort study, damage to the pelvic floor muscle was associated with older maternal age [17]. Thus, damage to the pelvic floor during vaginal delivery may lead to stress urinary incontinence in advanced maternal age women. However, researchers have not yet clarified the temporal recovery of pelvic floor function after vaginal delivery in women with advanced maternal age.

The female pelvic floor has 2 distinct functions: 1) contractile function reflecting the contractile strength of the pelvic floor muscle and 2) supporting function for protection against pelvic organ prolapse. The anteroposterior diameter of the levator hiatus, as measured by dynamic transperineal ultrasonography, can be a reliable parameter to assess the supporting and contractile functions of the pelvic floor [18-20]. Consequently, the aim of this study was to show a difference in temporal recovery of the anteroposterior diameter of the levator hiatus within 6 months postpartum period between women having their first delivery at an advanced age and those having their first delivery at a younger age, using dynamic transperineal ultrasound.

\section{METHODS}

An observational prospective study design was used to compare pelvic floor function in the postpartum period between women of advanced maternal age at first delivery and those of younger maternal age. Women who delivered for the first time at 35 years and/or older were defined as being at advanced maternal age. For example, a woman who delivered her first baby at 33 years of age and delivered the second at 37 years was defined as being of younger maternal age.

Seventeen women delivering a single baby at the University of Tokyo hospital were randomly recruited in the early puerperal period. We investigated pelvic floor function and urinary incontinence at about 6 weeks, 3 months, and 6 months postpartum from July 2008 through April 2009. Inclusion criteria were Japanese women living near the hospital and capable of visiting the hospital in the puerperal period, more than 20 years of age, vaginal delivery, no pregnancy complications, no mental disease, no ongoing urinary tract infection, and no neurological disorder.

Dynamic transperineal ultrasonography used to measure pelvic floor function was performed by a trained midwife using EUB-8500 (Hitachi Medical Co., Tokyo, Japan) with a 5-MHz 2D curved array ultrasound transducer placed on the perineum in the dorsosacral position $[19,20]$. The anteroposterior diameter of the levator hiatus is defined as the minimal distance between the poste- rior aspect of the pubic symphysis and the anterior border of the pubovisceral muscle in the mid-sagittal plane (Figure 1) [20-24]. All measurements were repeated 3 times while women were asked to voluntary contract the pelvic floor muscle as much as possible for $10 \mathrm{~s}$. The strength of the pelvic floor muscle contraction was not standardized. The women were not allowed to observe the screen in order to avoid any biofeedback effect. The mean of the 3 measurements at rest and during contraction were used for analysis. With regard to the accuracy of the measurements, intraclass correlation coefficients $\left(\mathrm{ICC}_{1,1}\right)$ at each investigation time point was 0.918 0.949 at rest and $0.894-0.942$ during contraction.

Demographic data (age, prepregnancy body mass index (BMI), history of pregnancy, and mode of past delivery) and pregnancy and delivery outcomes (gestational age, birth weight, total length of labor, perineal trauma, etc.) were obtained from the medical chart. All the women were asked to complete the International Consultation on Incontinence Questionnaire-Short Form (ICIQ-SF) [25] before commencing each investigation (6 weeks, 3 months, and 6 months postpartum). ICIQ-SF consists of 4 questions regarding type, frequency, and amount of urinary incontinence and quality of life. The women who manifested symptoms more than once per week by 6 months after delivery were diagnosed with urinary incontinence. The study protocol was approved by the Research Ethics Committee of the Graduate

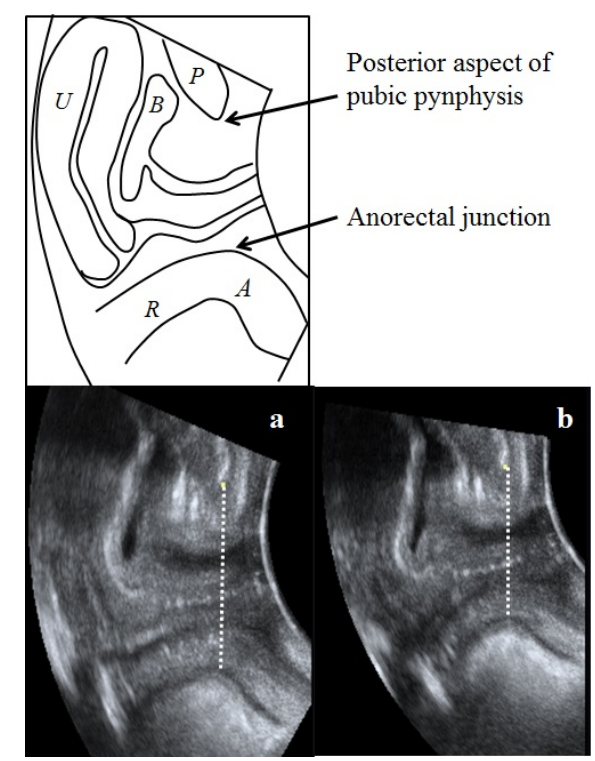

Figure 1. Antero-posterior diameter of the levator hiatus in the midsagittal plane by transperineal ultrasound: the minimal distance between the posterior aspect of the pubic symphysis and the anterior border of the pubovisceral muscle in the midsagittal plane at rest (a) and contraction (b). From [24] with permission. 
School of Medicine, the University of Tokyo. Each participant read and gave written informed consent.

Statistical analysis was performed using SPSS version 15 (SPSS Inc., Chicago, IL, USA). All $p$-values were 2 -sided. $p<0.05$ was considered statistically significant. The mean and standard deviation (SD) were used for the descriptive data. The physical data and pregnancy and delivery outcomes were compared between the advanced maternal age and younger maternal age women using Student's $t$ test, the Mann-Whitney U test, and Fisher's exact test. A linear mixed model was used to examine temporal changes in the pelvic floor between the 2 groups of women at first delivery. Multiple comparisons were performed using the Bonferroni method. Student's $t$-test was used to compare the pelvic floor function between the 2 groups at each time point.

\section{RESULT}

Seventeen postpartum women were examined by transperineal ultrasonography within 6 weeks to 6 months after vaginal delivery at a gynecological outpatient clinic. The mean $( \pm \mathrm{SD})$ age was $35.5 \pm 3.5$ years, and the mean BMI was $21.1 \pm 3.2 \mathrm{~kg} / \mathrm{m}^{2}$ at 6 weeks postpartum (Table 1). Of the 17 women tested, 14 (82.4\%) were primiparous and 3 women had once experienced vaginal delivery. Nine women $(52.9 \%)$ experienced their first delivery at 35 years and/or older. Five women (29.4\%) manifested stress urinary incontinence within 6 months after vaginal delivery, and all women with stress urinary incontinence experienced urinary incontinence during pregnancy. Four of the 5 women $(80 \%)$ with postpartum urinary incontinence were of advanced maternal age. The advanced maternal age women had heavier prepregnancy weight than the younger maternal age women $(p=0.028)$ while there was no significant difference in other demographic data and delivery outcomes between the 2 groups (Tables 2 and 3 ).

The anteroposterior diameter of the levator hiatus at rest was significantly greater with advanced maternal age

Table 1. Physical description of postpartum women.

\begin{tabular}{|c|c|c|c|}
\hline \multicolumn{4}{|c|}{$n=17$} \\
\hline & 6 weeks & 3 months & 6 months \\
\hline Age (years) & $35.5 \pm 3.5$ & - & - \\
\hline Height $(\mathrm{cm})$ & $157.7 \pm 5.0$ & - & - \\
\hline Weight $(\mathrm{kg})$ & $54.1 \pm 7.6$ & $53.5 \pm 7.3$ & $53.2 \pm 7.6$ \\
\hline $\begin{array}{l}\text { Body mass index } \\
\qquad\left(\mathrm{kg} / \mathrm{m}^{2}\right)\end{array}$ & $21.1 \pm 3.2$ & $20.9 \pm 3.1$ & $20.7 \pm 3.2$ \\
\hline $\begin{array}{c}\text { Abdominal } \\
\text { circumference }(\mathrm{cm})\end{array}$ & $76.6 \pm 7.0$ & $75.1 \pm 6.7$ & $74.6 \pm 7.6$ \\
\hline
\end{tabular}

Data are mean \pm SD. at 3 and 6 months postpartum $(61.8 \pm 4.9 \mathrm{~mm}$ vs. $55.2 \pm$ $3.8 p=0.008,57.4 \pm 3.7$ vs. $50.1 \pm 4.7 p=0.003$, respectively; Figure 2), and a trend was observed at 6 weeks postpartum $(p=0.06)$. The anteroposterior diameter of the levator hiatus during maximum contraction was significantly greater with advanced maternal age at each of the 3 investigation time points $(p<0.05$; Figure $3)$. Among the continent women, the anteroposterior diameter of the levator hiatus at rest was significantly greater among the advanced maternal age women at 6 months postpartum $(57.3 \pm 4.6 \mathrm{~mm}$ vs. $48.8 \pm 3.6, p=$ 0.004 ; Figure 4). In addition, the anteroposterior diameter of the levator hiatus during maximum contraction was significantly greater in the advanced maternal age women at all investigation time points $(p<0.05$; Figure 5). However, among the advanced maternal age women, all parameters of the anteroposterior diameter of the levator hiatus were not significantly different among the women with and without stress urinary incontinence at all investigation time points (Figures 6 and 7).

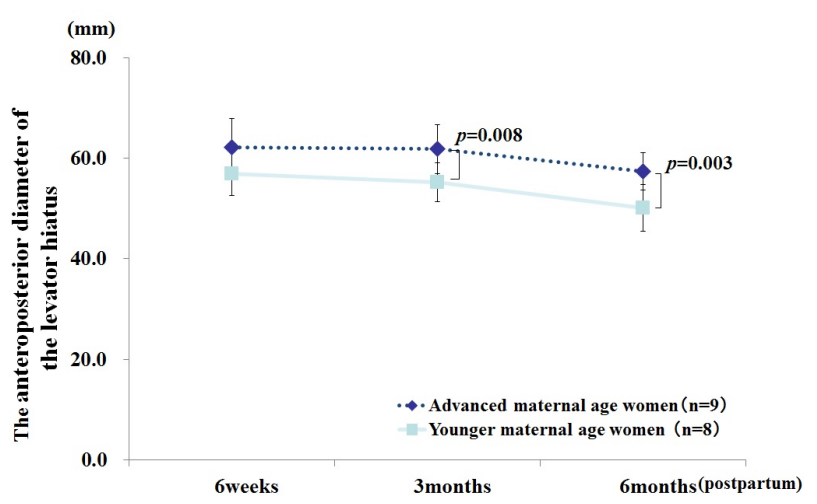

Figure 2. Anteroposterior diameter of the levator hiatus at rest among all women. General linear mixed model. Fixed effect: advanced maternal age $(p=0.006)$ and time $(p<0.001)$, random effect: participants.

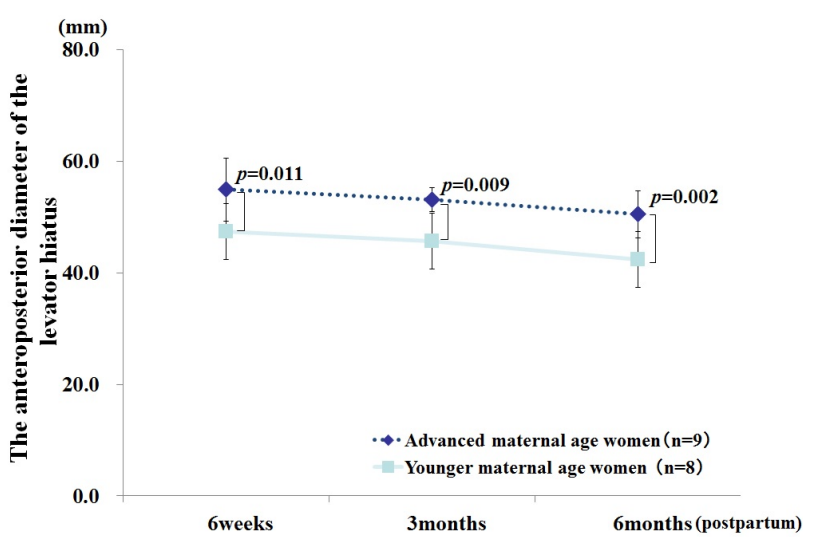

Figure 3. Anteroposterior diameter of the levator hiatus at contraction among all women. General linear mixed model. Fixed effect: advanced maternal age $(p=0.001)$ and time $(p=0.001)$, random effect: participants. 


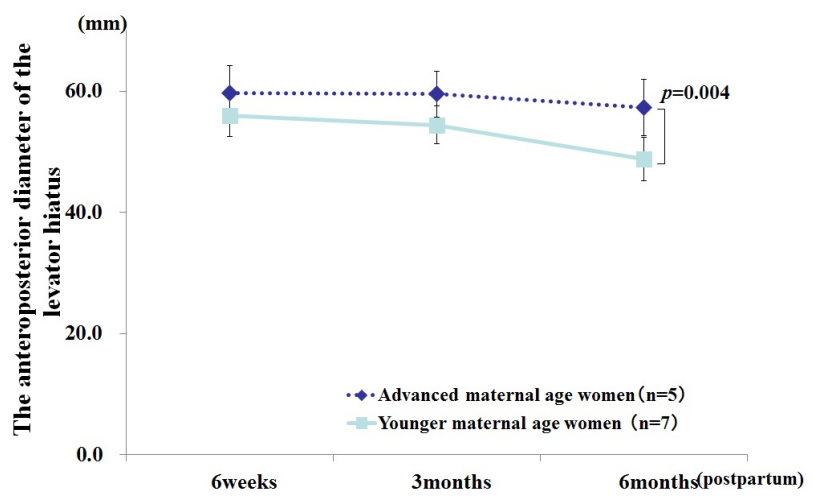

Figure 4. Anteroposterior diameter of the levator hiatus at rest among continent women. General linear mixed model. Fixed effect: advanced maternal age $(p=0.011)$ and time $(p<0.001)$, random effect: participants.

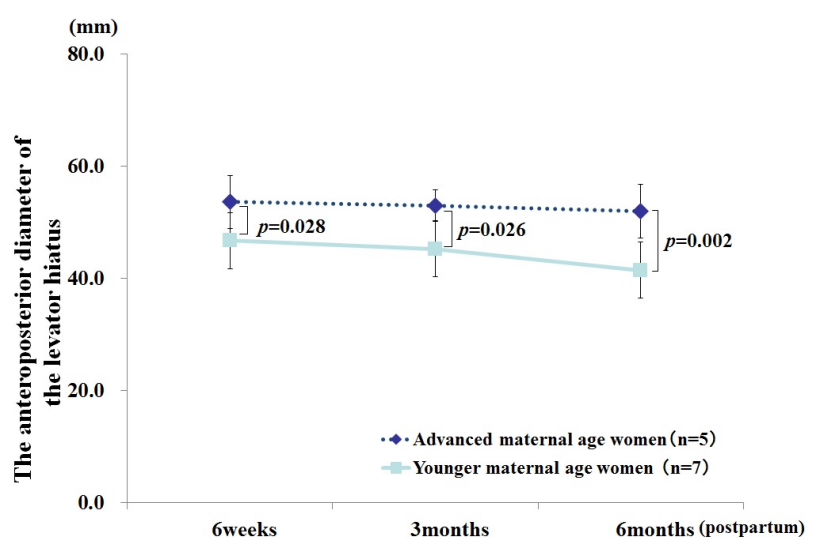

Figure 5. Anteroposterior diameter of the levator hiatus at contraction among continent women. General linear mixed model. Fixed effect: advanced maternal age $(p=0.004)$ and time $(p=$ 0.023), random effect: participants.

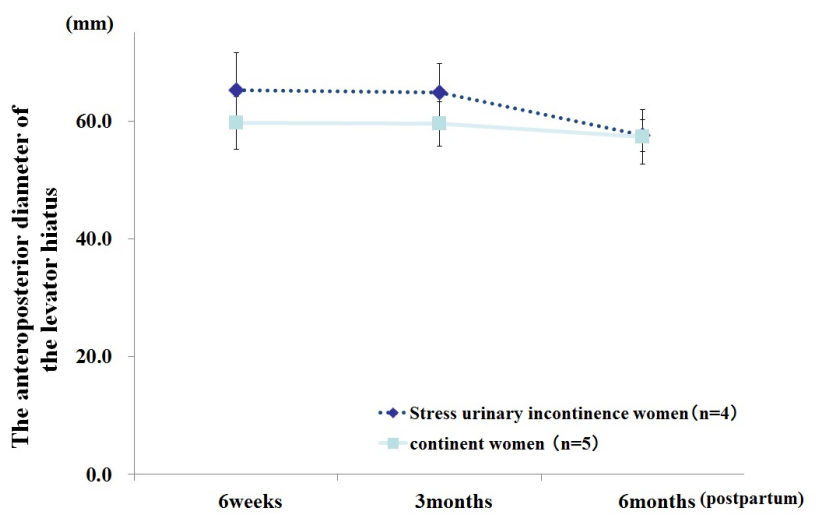

Figure 6. Anteroposterior diameter of the levator hiatus at rest among women of advanced maternal age. General linear mixed model. Fixed effect: stress urinary incontinence $(p=0.993)$ and time $(p=0.040)$, random effect: participants.

\section{DISCUSSION}

The main objective of this study was to clarify the temporal recovery of pelvic floor function after vaginal de-

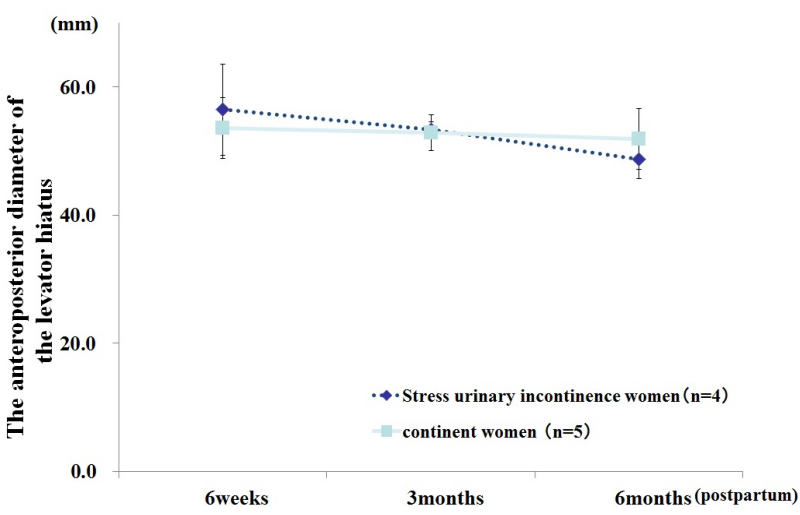

Figure 7. Anteroposterior diameter of the levator hiatus at contraction among women of advanced maternal age. General linear mixed model. Fixed effect: stress urinary incontinence ( $p$ $=0.231)$ and time $(p=0.003)$, random effect: participants.

livery in women of advanced maternal age at first delivery by comparing the pelvic function with that of women of younger maternal age at first delivery, using the transperineal ultrasound approach. To our knowledge, this is the first study revealing that the anteroposterior diameter of the levator hiatus at rest was significantly greater in the advanced maternal age women than in the younger maternal age women at 3 months postpartum. The anteroposterior diameter of the levator hiatus at rest was also significantly greater in the women of advanced maternal age at first delivery than in the younger maternal age women at 6 months postpartum. These findings demonstrated that the advanced maternal age women at first delivery presented with delayed recovery of pelvic floor function after vaginal delivery, regardless of stress urinary incontinence.

The association of advanced age at first delivery with more severe damage of the pelvic floor after vaginal delivery may be because of a higher incidence of adverse obstetric complications caused by gradual decrease in myometrium function with increasing age [17,26,27]. Kearney et al. [17] used magnetic resonance imaging to investigate the pelvic floor after delivery. The study reported that damage to the pelvic floor muscle was associated with advanced maternal age because there tends to be prolonged second stage of labor and instrumental delivery. Main et al. [26] studied 8,496 low-risk, term nulliparous women in spontaneous labor and concluded that there was an increasing need for more operative vaginal deliveries and caesarean deliveries with advancing maternal age because of a longer second stage of labor. On the other hands, this study showed that the anteroposterior diameter of the levator hiatus at rest at 6 weeks postpartum tended to be greater in women of advanced maternal age than the younger aged women, although the delivery outcomes were not significantly different between two groups. Therefore, it might be concluded that 
Table 2. Physical description of postpartum women at 6 weeks.

\begin{tabular}{|c|c|c|c|c|}
\hline & All women $(n=17)$ & Advanced maternal age $(n=9)$ & Younger maternal age $(n=8)$ & $p$ \\
\hline Age (years) & $35.5 \pm 3.5$ & $37.1 \pm 1.4$ & $33.8 \pm 4.3$ & $0.07^{\mathrm{a}}$ \\
\hline$\geq 35$ years & $12(70.6)$ & $9(100.0)$ & $3(37.5)$ & $0.01^{\mathrm{b}}$ \\
\hline Height (cm) & $157.7 \pm 5.0$ & $159.9 \pm 4.5$ & $161.0 \pm 5.5$ & $0.80^{\mathrm{a}}$ \\
\hline Weight $(\mathrm{kg})$ & $54.1 \pm 7.6$ & $56.8 \pm 8.5$ & $51.1 \pm 5.5$ & $0.12^{\mathrm{a}}$ \\
\hline Body mass index $\left(\mathrm{kg} / \mathrm{m}^{2}\right)$ & $21.1 \pm 3.2$ & $22.3 \pm 3.6$ & $19.8 \pm 2.2$ & $0.11^{\mathrm{a}}$ \\
\hline Abdominal circumference $(\mathrm{cm})$ & $76.6 \pm 7.0$ & $78.4 \pm 8.1$ & $74.6 \pm 5.3$ & $0.27^{\mathrm{a}}$ \\
\hline
\end{tabular}

Data are mean $\pm \mathrm{SD}$ or $n(\%) .{ }^{\mathrm{a}}$ Student's t test, ${ }^{\mathrm{b}}$ Fisher's exact test.

Table 3. Pregnancy and delivery outcomes.

\begin{tabular}{|c|c|c|c|c|}
\hline & All women $(n=17)$ & Advanced maternal age $(n=9)$ & Younger maternal age $(n=8)$ & $p$ \\
\hline \multicolumn{5}{|l|}{ Mother } \\
\hline Primigravid women & $14(82.4)$ & $9(100.0)$ & $5(62.5)$ & $0.08^{\mathrm{c}}$ \\
\hline Prepregnancy weight (kg) & $54.1 \pm 8.5$ & $58.2 \pm 8.9$ & $49.5 \pm 5.3$ & $0.028^{\mathrm{a}}$ \\
\hline $\begin{array}{l}\text { Prepregnancy body mass index } \\
\left(\mathrm{kg} / \mathrm{m}^{2}\right)\end{array}$ & $21.1 \pm 3.6$ & $22.8 \pm 3.8$ & $19.1 \pm 2.2$ & $0.03^{\mathrm{a}}$ \\
\hline Gestational weight gain (kg) & $8.2 \pm 3.4$ & $7.6 \pm 3.2$ & $8.9 \pm 3.7$ & $0.76^{\mathrm{b}}$ \\
\hline Total time of labor (min) & $476.4 \pm 390.0$ & $592.2 \pm 493.2$ & $346.3 \pm 184.7$ & $0.19^{\mathrm{a}}$ \\
\hline First stage & $385.8 \pm 348.1$ & $478.7 \pm 440.8$ & $266.4 \pm 119.3$ & $0.47^{\mathrm{b}}$ \\
\hline Second stage & $112.0 \pm 113.5$ & $108.1 \pm 129.9$ & $117.0 \pm 98.3$ & $0.84^{\mathrm{b}}$ \\
\hline \multicolumn{5}{|l|}{ Treatment in delivery } \\
\hline Induction & $8(47.1)$ & $1(11.1)$ & $3(37.5)$ & $0.29^{\mathrm{c}}$ \\
\hline $\begin{array}{l}\text { Perineal trauma (episiotomy or } \\
\text { perineal tear) }\end{array}$ & $17(100.0)$ & $9(100.0)$ & $8(100.0)$ & $1.00^{\mathrm{c}}$ \\
\hline \multicolumn{5}{|l|}{ Experience of SUI } \\
\hline During pregnancy & $13(76.5)$ & $7(77.8)$ & $6(75.0)$ & $1.00^{\mathrm{c}}$ \\
\hline Within 6 months after delivery & $5(29.4)$ & $4(44.4)$ & $1(12.5)$ & $0.29^{\mathrm{c}}$ \\
\hline \multicolumn{5}{|l|}{ Baby } \\
\hline Gestational age at delivery & $274.4 \pm 10.1$ & $275.4 \pm 8.0$ & $273.3 \pm 12.6$ & $0.67^{\mathrm{a}}$ \\
\hline Birth weight (g) & $2926.5 \pm 363.4$ & $2982.0 \pm 339.3$ & $2864.0 \pm 402.4$ & $0.52^{\mathrm{a}}$ \\
\hline Head circumference $(\mathrm{cm})$ & $33.1 \pm 1.5$ & $33.6 \pm 1.6$ & $32.7 \pm 1.5$ & $0.26^{\mathrm{a}}$ \\
\hline
\end{tabular}

Data are mean \pm SD or $n(\%)$; ${ }^{a}$ Student's t test; ${ }^{b}$ Mann-Whitney U test; ${ }^{c}$ Fisher's exact test; SUI: stress urinary incontinence.

women having their first vaginal delivery at an advanced maternal age are likely to experience not only traumatic damage to the pelvic floor during vaginal delivery but also sustained damage by the weight of the fetus during pregnancy.

In our study, 4 of the 5 women (80\%) who manifested postpartum stress urinary incontinence were at an advanced maternal age. This result confirmed the result of a previous study reporting the higher prevalence of stress urinary incontinence after spontaneous vaginal delivery in older primiparous women $[4,12,14]$. DeLancey et al. [28] reported that women with stress urinary incontinence had weak urethral closure ability caused by decreased supporting function of the pelvic floor. In addition, several studies reported the relationship between stress urinary incontinence and impaired supporting function of the pelvic floor [16,20]. Consequently, it is reasonable that weak urethral closure caused by impaired supporting function is related to the incidence of postpartum stress urinary incontinence. In this study, the anteroposterior diameter of the levator hiatus during contraction was greater among the advanced maternal age women than among the younger women at each investigation time point. This implies that advanced primiparous age is more likely associated with stress urinary incontinence through weak urethral closure caused by impaired supporting function and delayed pelvic floor recovery following vaginal delivery.

It is interesting to note that among the advanced maternal age women in our study, the anteroposterior di- 
ameter of the levator hiatus at rest was not significantly different between the women with and without stress urinary incontinence. Identification of a woman requiring care during the recovery of the pelvic floor is difficult in the early postpartum period because health care providers identify women with pelvic floor dysfunction by assessing symptoms of stress urinary incontinence, which appears only when abdominal pressure increases suddenly. In other words, postpartum women with weak pelvic function do not experience incontinent episodes in the postpartum period only because of reduced chance for physical exertion (e.g., sneezing, coughing, or jumping). Therefore, stress urinary incontinence may be one of the indicators of weak pelvic floor function. The clinical significance of this study is that it indicates that advanced maternal age at first delivery is a risk factor of pelvic floor dysfunction, regardless of stress urinary incontinence. There is an increasing need for management among women of advanced maternal age to help recover pelvic floor function following delivery.

This study has some limitations. The first limitation is its small sample size. The relationship between pelvic floor function and maternal age, after controlling for physical data, could not be investigated in this study. In addition, this study was not controlled by parity. It included both primiparous and multiparous women because pelvic floor function in all multiparous women younger than 35 years old at first delivery was not different from that of younger primiparous women. Considering the result of a previous study [27] reporting that increased incidence of caesarean sections in labor was only found among nulliparous women of advanced maternal age, the maternal age at first delivery might be an important factor for an incidence of adverse obstetric complications and severe damage to pelvic floor function in the postpartum period. The second limitation is the lack of a biological explanation for impaired pelvic floor function with advanced maternal age at first delivery. From the perspective of the biological relationship between muscle function and aging, the age difference between advanced maternal age and younger maternal age in this study is small. The biological mechanism for susceptibility to damage to the pelvic floor with advanced age has not been clarified. Further studies are necessary to biologically investigate the effects of advanced maternal age on the damage to the pelvic floor during vaginal delivery and its recovery, in a longer longitudinal period with a larger sample size.

In conclusion, this study found that the recovery of pelvic floor function may be delayed in women of advanced maternal age at first delivery because of damage to the pelvic floor during pregnancy and vaginal delivery, resulting in increased incidence of stress urinary incontinence. Therefore, treatment of the pelvic floor in the postpartum period is important for preventing stress urinary incontinence, especially in women of advanced maternal age at first delivery.

\section{ACKNOWLEDGEMENTS}

This study was supported by JSPS KAKENHI Grant Number 20592573. The authors are grateful to the participants for their cooperation. The authors have no conflicts of interest or relationships to disclose.

\section{REFERENCES}

[1] Kinchen, K.S., Burgio, K., Diokno, A.C., Fultz, N.H., Bump, R. and Obenchain, R. (2003) Factors associated with women's decisions to seek treatment for urinary incontinence. Journal of Women's Health, 12, 687-698. doi:10.1089/154099903322404339

[2] Tennstedt, S.L., Fitzgerald, M.P., Nager, C.W., Xu, Y., Zimmern, P., Kraus, S., et al. (2007) Quality of life in women with stress urinary incontinence. International Urogynecology Journal, 18, 543-549. doi:10.1007/s00192-006-0188-5

[3] Schytt, E., Lindmark, G. and Waldenstrom, U. (2004) Symptoms of stress incontinence 1 year after childbirth: Prevalence and predictors in a national swedish sample. Acta Obstetricia et Gynecologica Scandinavica, 83, 928936.

[4] Glazener, C.M., Herbison, G.P., MacArthur, C., Lancashire, R., McGee, M.A., Grant, A.M., et al. (2006) New postnatal urinary incontinence: Obstetric and other risk factors in primiparae. BJOG: An International Journal of Obstetrics \& Gynaecology, 113, 208-217. doi:10.1111/j.1471-0528.2005.00840.x

[5] Baydock, S.A., Flood, C., Schulz, J.A., MacDonald, D., Esau, D., Jones, S., et al. (2009) Prevalence and risk factors for urinary and fecal incontinence four months after vaginal delivery. Journal of Obstetrics and Gynaecology Canada, 31, 36-41.

[6] Fritel, X., Fauconnier, A., Levet, C. and Benifla, J.L. (2004) Stress urinary incontinence 4 years after the first delivery: A retrospective cohort survey. Acta Obstetricia et Gynecologica Scandinavica, 83, 941-945.

[7] MacArthur, C., Glazener, C.M., Wilson, P.D., Lancashire, R.J., Herbison, G.P. and Grant, A.M. (2006) Persistent urinary incontinence and delivery mode history: A sixyear longitudinal study. BJOG: An International Journal of Obstetrics \& Gynaecology, 113, 218-224. doi:10.1111/j.1471-0528.2005.00818.x

[8] Wesnes, S.L., Hunskaar, S., Bo, K. and Rortveit, G. (2009) The effect of urinary incontinence status during pregnancy and delivery mode on incontinence postpartum. A cohort study. BJOG: An International Journal of Obstetrics \& Gynaecology, 116, 700-707. doi:10.1111/j.1471-0528.2008.02107.x

[9] Foldspang, A., Hvidman, L., Mommsen, S. and Nielsen, J.B. (2004) Risk of postpartum urinary incontinence associated with pregnancy and mode of delivery. Acta Ob- 
stetricia et Gynecologica Scandinavica, 83, 923-927.

[10] Rortveit, G., Daltveit, A.K., Hannestad, Y.S., Hunskaar, S. (Norwegian EPINCONT Study) (2003) Urinary incontinence after vaginal delivery or cesarean section. The New England Journal of Medicine, 348, 900-907. doi:10.1056/NEJMoa021788

[11] El-Hefnawy, A.S. and Wadie, B.S. (2011) Severe stress urinary incontinence: Objective analysis of risk factors. Maturitas, 68, 374-377. doi:10.1016/j.maturitas.2011.01.005

[12] Groutz, A., Rimon, E., Peled, S., Gold, R., Pauzner, D., Lessing, J.B., et al. (2004) Cesarean section: Does it really prevent the development of postpartum stress urinary incontinence? A prospective study of 363 women one year after their first delivery. Neurourology \& Urodynamics, 23, 2-6. doi:10.1002/nau.10166

[13] Hijaz, A., Sadeghi, Z., Byrne, L., Hou, J.C. and Daneshgari, F. (2012) Advanced maternal age as a risk factor for stress urinary incontinence: A review of the literature. International Urogynecology Journal, 23, 395-401. doi:10.1007/s00192-011-1562-5

[14] Dietz, H.P. and Wilson, P.D. (2005) Childbirth and pelvic floor trauma. Best Practice \& Research Clinical Obstetrics \& Gynaecology, 19, 913-924. doi:10.1016/i.bpobgyn.2005.08.009

[15] Ministry of Health, Labour and Welfare. (2010) Nationality in specified report of vital statistics. http://www.mhlw.go.jp/english/index.html

[16] DeLancey, J.O., Kearney, R., Chou, Q., Speights, S. and Binno, S. (2003) The appearance of levator ani muscle abnormalities in magnetic resonance images after vaginal delivery. Obstetrics \& Gynecology, 101, 46-53. doi:10.1016/S0029-7844(02)02465-1

[17] Kearney, R., Miller, J.M., Ashton-Miller, J.A. and DeLancey, J.O. (2006) Obstetric factors associated with levator ani muscle injury after vaginal birth. Obstetrics \& Gynecology, 107, 144-149. doi:10.1097/01.AOG.0000194063.63206.1c

[18] Whittaker, J.L., Thompson, J.A., Teyhen, D.S. and Hodges, P. (2007) Rehabilitative ultrasound imaging of pelvic floor muscle function. Journal of Orthopaedic \& Sports Physical Therapy, 37, 487-498.

[19] Dietz, H.P., Shek, C. and Clarke, B. (2005) Biometry of the pubovisceral muscle and levator hiatus by three-dimensional pelvic floor ultrasound. Ultrasound in Obstetrics \& Gynecology, 25, 580-585. doi:10.1002/uog.1899

[20] Huang, W.C., Yang, S.H. and Yang, J.M. (2006) Ana- tomical and functional significance of urogenital hiatus in primary urodynamic stress incontinence. Ultrasound in Obstetrics \& Gynecology, 27, 71-77. doi:10.1002/uog.2649

[21] Weinstein, M.M., Jung, S.A., Pretorius, D.H., Nager, C.W., den Boer, D.J. and Mittal, R.K. (2007) The reliability of puborectalis muscle measurements with 3-dimensional ultrasound imaging. American Journal of $\mathrm{Ob}$ stetrics \& Gynecology, 197, 68.e1-e6.

[22] Braekken, I.H., Majida, M., Ellstrom-Engh, M., Dietz, H.P., Umek, W. and Bo, K. (2008) Test-retest and intra-observer repeatability of two-, three- and four-dimensional perineal ultrasound of pelvic floor muscle anatomy and function. International Urogynecology Journal, 19, 227235. doi:10.1007/s00192-007-0408-7

[23] Kruger, J.A., Heap, S.W., Murphy, B.A. and Dietz, H.P. (2008) Pelvic floor function in nulliparous women using three-dimensional ultrasound and magnetic resonance imaging. Obstetrics \& Gynecology, 111, 631-638.

[24] Yoshida, M., Murayama, R., Haruna, M., Matsuzaki, M., Yoshimura, K., Murashima, S., et al. (2012) Longitudinal comparison study of pelvic floor function between women with and without stress urinary incontinence after vaginal delivery. Journal of Medical Ultrasonics, 40, 125-131. doi:10.1007/s10396-012-0396-1

[25] Gotoh, M., Homma, Y., Funahashi, Y., Matsukawa, Y. and Kato, M. (2009) Psychometric validation of the Japanese version of the international consultation on incontinence questionnaire-short form. International Journal of Urology, 16, 303-306. doi:10.1111/j.1442-2042.2008.02237.x

[26] Main, D.M., Main, E.K. and Moore II, D.H. (2000) The relationship between maternal age and uterine dysfunction: A continuous effect throughout reproductive life. American Journal of Obstetrics \& Gynecology, 182, 1312-1320. doi:10.1067/mob.2000.106249

[27] Wang, Y., Tanbo, T., Abyholm, T. and Henriksen, T. (2011) The impact of advanced maternal age and parity on obstetric and perinatal outcomes in singleton gestations. Archives of Gynecology \& Obstetrics, 284, 31-37. doi:10.1007/s00404-010-1587-X

[28] DeLancey, J.O., Miller, J.M., Kearney, R., Howard, D., Reddy, P., Umek, W., et al. (2007) Vaginal birth and de novo stress incontinence: Relative contributions of urethral dysfunction and mobility. Obstetrics \& Gynecology, 110, 354-362. doi:10.1097/01.AOG.0000270120.60522.55 